\title{
Corticosterone infused into the dorsal striatum selectively enhances memory consolidation of cued water-maze training
}

\author{
Gina L. Quirarte, ${ }^{1,3}$ I. Sofía Ledesma de la Teja, ${ }^{1}$ Miriam Casillas, ${ }^{1}$ Norma Serafín, ${ }^{1}$ \\ Roberto A. Prado-Alcalá, ${ }^{1}$ and Benno Roozendaal ${ }^{2}$ \\ ${ }^{1}$ Departamento de Neurobiología Conductual y Cognitiva, Instituto de Neurobiología, Universidad Nacional Autónoma de México, \\ Campus Juriquilla Querétaro 76230, México; ${ }^{2}$ Department of Neuroscience, Section Anatomy, University Medical Center \\ Groningen, University of Groningen, 9713 AV Groningen, The Netherlands
}

\begin{abstract}
Glucocorticoid hormones enhance memory consolidation of hippocampus-dependent spatial/contextual learning, but little is known about their possible influence on the consolidation of procedural/implicit memory. Therefore, in this study we examined the effect of corticosterone $(2,5$, or $10 \mathrm{ng})$ infused into the dorsal striatum of male Wistar rats immediately after training on either a cued or spatial version of the water maze. We found that corticosterone dosedependently enhanced 48-h retention of the cued training without affecting the retention of the spatial training. These findings indicate that corticosterone acts within the dorsal striatum to enhance memory consolidation of procedural/ implicit training.
\end{abstract}

It is well established that adrenocortical hormones, released during stressful stimulation, enhance the consolidation of memory of emotionally arousing experiences (de Kloet et al. 1999; Roozendaal 2000; Joëls et al. 2006; Sandi and Pinelo-Nava 2007; Roozendaal et al. 2008). Most studies have examined glucocorticoid effects on memory consolidation in relation to hippocampal function in experiments using tasks that have a strong spatial and/or contextual component, including water-maze spatial training, contextual fear conditioning, and inhibitory avoidance training (Roozendaal and McGaugh 1996; Pugh et al. 1997; Sandi et al. 1997; Roozendaal et al. 1999a). Similarly, studies in human subjects emphasized an involvement of cortisol in modulating the consolidation of declarative memory (Buchanan and Lovallo 2001; Abercrombie et al. 2003; Andreano and Cahill 2006; Kuhlmann and Wolf 2006). However, growing evidence indicates that glucocorticoid hormones also enhance memory consolidation of training that does not appear to depend crucially on an intact hippocampus. We recently reported that glucocorticoids enhance the consolidation of memory of conditioned taste aversion training when infused into the insular cortex or basolateral complex of the amygdala, but not into the hippocampus (Miranda et al. 2008). Other studies indicated that glucocorticoids administered systemically enhance memory consolidation of hippocampus-independent auditory cue fear conditioning (Zorawski and Killcross 2002; Hui et al. 2004) and object recognition (Okuda et al. 2004; Roozendaal et al. 2006).

Surprisingly little is known regarding a possible influence of glucocorticoids on the consolidation of memory of procedural or nondeclarative training. Although several studies have now reported that glucocorticoid administration, stress exposure, or an anxious emotional state, either shortly before training or before retention testing, shifts the relative use of spatial/declarative ("cognitive") versus procedural/implicit ("habit") response strategies (Kim et al. 2001; Schwabe et al. 2008, 2009; Packard 2009a), these studies did not investigate whether glucocorticoids affect the

${ }^{3}$ Corresponding author.

E-mail ginaqui@servidor.unam.mx; fax 52-442-238-1046.

Article is online at http://www.learnmem.org/cgi/doi/10.1101//m.1493609. consolidation of procedural memory. Moreover, findings suggest that such a bias in learning strategy is predominantly attributable to a stress-induced alteration of hippocampal function rather than by a direct modulation of procedural performance (Packard 2009a). Another study investigating the effects of glucocorticoids on human memory processing during sleep reported that the administration of the synthetic glucocorticoid dexamethasone shortly before sleep did not influence performance on an implicit mirror-tracing skills task as assessed several hours later (Plihal and Born 1999).

We recently reported that corticosterone, the major endogenous glucocorticoid in rodents, infused into the dorsal striatum of rats immediately after inhibitory avoidance training, enhanced later retention of this experience (Medina et al. 2007). Extensive evidence indicates that learning and memory of procedural training depends critically on the dorsal striatum (i.e., caudate nucleus) (Packard and White 1991; Packard et al. 1994; Packard and Knowlton 2002; Prado-Alcalá et al. 2003; Wachter et al. 2009). As we found further that such a striatal administration of corticosterone did not enhance memory of the contextual representations of the apparatus or that of the shock experience per se, such findings suggest the possibility that the corticosterone might have enhanced memory of some procedural or implicit aspects of inhibitory avoidance training. However, as this could not be assessed directly, we now explicitly investigated whether glucocorticoids act in the dorsal striatum to enhance the consolidation of memory of procedural training. Thus, the present study investigated whether immediate post-training infusions of corticosterone administered into the dorsal striatum of rats influenced memory consolidation of training on a cued version of the water maze, a procedural learning task that is known to depend critically on functioning of the dorsal striatum (Packard et al. 1994; Packard and Knowlton 2002). Other groups of rats received intrastriatal infusions of corticosterone immediately after training on a hippocampus-dependent spatial version of the task.

Adult male Wistar rats (250-350 g at the time of surgery) obtained from the breeding colony at the Instituto de Neurobiología, Universidad Nacional Autónoma de México, were kept individually in a temperature-controlled $\left(24^{\circ} \mathrm{C}\right)$ colony room and maintained on a standard 12-h light/12-h dark cycle (07:00-1900 h 
lights on) with ad libitum access to food and water. Under sodium pentobarbital anesthesia (50 mg/kg, ip), bilateral guide cannulae (11-mm long; 23 gauge) were implanted into the anterior division of the dorsal striatum (coordinates: anteroposterior, $0.0 \mathrm{~mm}$ from bregma; mediolateral, $\pm 3.2 \mathrm{~mm}$ from midline; dorsoventral, $-4.2 \mathrm{~mm}$ from skull surface) according to the atlas of Paxinos and Watson (1998). The cannulae were affixed to the skull with two anchoring screws and dental cement. Stylets (11$\mathrm{mm}$ long 00-insect dissection pins) were inserted into each cannula to maintain patency and removed only for the infusion of drugs. The rats were allowed to recover for a minimum of $7 \mathrm{~d}$ before initiation of training.

For both cued and spatial training, the rats were trained in a water maze consisting of a black circular plastic tank, $1.54 \mathrm{~m}$ in diameter and $0.60 \mathrm{~m}$ in height. The tank was filled with water $\left(25 \pm 1^{\circ} \mathrm{C}\right)$ to a depth of $21 \mathrm{~cm}$. The maze was located in a room containing several salient extramaze cues. Four starting positions were equally spaced around the pool perimeter, dividing it into four quadrants. For cued training, the rat was placed in the tank at one of the four designated starting points, facing the wall, and allowed to escape onto a visible platform. The escape platform $(20 \times 20 \mathrm{~cm})$ was made of Plexiglas and marked by a rubber ball mounted on top of the platform. After mounting the platform, the rat remained there for $20 \mathrm{sec}$ and was then placed in a holding box for $30 \mathrm{sec}$ until the start of the next trial. A total of eight trials were given and the platform was moved to a different location on each trial, such that each of the four quadrants contained the escape platform twice. The locations of the starting points were arranged such that distance to the escape platform (i.e., proximal or distal) and location of the platform relative to the starting point (i.e., left or right) were counterbalanced across trials. For spatial training, the escape platform was placed $25-\mathrm{cm}$ away from the edge of the pool in a fixed location and was submerged $2 \mathrm{~cm}$ below the water surface and could not be seen by the rats. On both tasks, latencies to mount the escape platform were recorded using the Polytrack system (San Diego Instruments, Inc.) and used as a measure of acquisition. Retention on both tasks was tested $48 \mathrm{~h}$ after training and consisted of one additional trial; the latency to mount the escape platform on this trial was used as the measure of retention.

Corticosterone (2, 5, or $10 \mathrm{ng}$; Sigma-Aldrich) was administered into the dorsal striatum immediately after training on either task. Corticosterone was first dissolved in 100\% ethanol and subsequently diluted in saline to reach the appropriate concentration. The final ethanol concentration was $2 \%$. Bilateral infusions of drug or an equivalent volume of vehicle (2\% ethanol in saline) into the dorsal striatum were made by using 30-gauge injection needles connected to $10-\mu \mathrm{L}$ Hamilton microsyringes with polyethylene tubing. The injection needles protruded 1.0 $\mathrm{mm}$ beyond the tip of the cannulae and a $1.0-\mu \mathrm{L}$ injection volume per hemisphere was infused over a period of $60 \mathrm{sec}$ with an automated syringe pump (WPI, model 220i). The injection needles were retained within the guide cannulae for an additional $60 \mathrm{sec}$ to maximize diffusion away from the injector tip.

Upon completion of behavioral testing, the rats were anesthetized with an overdose of sodium pentobarbital and perfused transcardially with isotonic saline, followed by $4 \%$ formaldehyde. After decapitation, the brains were removed and immersed in a $4 \%$ formaldehyde solution. Coronal sections of $50 \mu \mathrm{m}$ were cut on a cryostat, stained with cresyl violet, and examined under a light microscope by an observer blind to drug treatment condition. Figure 1 shows the location of injection needle tips in the dorsal striatum of rats trained on the cued version of the water maze. Histological examination of rats trained on the spatial version of the task revealed similar results (data not shown). Six rats with improper injection needle placements were excluded from statistical analysis.

Figure 2 shows escape latencies during the training session and the 48-h retention test of rats trained on the cued version of the water maze and given immediate post-training infusions of corticosterone into the dorsal striatum. Split-Plot ANOVA revealed that the four groups did not differ during training, before drug treatment $\left(F_{(3,48)}=0.77, P=0.52\right)$, but that there was a significant trial effect $\left(F_{(7,336)}=29.47, P<0.0001\right)$. The group $\times$ trial interaction was not statistically significant $\left(F_{(21,336)}=0.90, P=\right.$ $0.59)$. The animals learned the task as indicated by a progressive reduction of escape latencies during the course of training. Oneway ANOVA for escape latencies on the 48-h retention test indicated a highly significant treatment effect $\left(F_{(3,48)}=5.96, P<\right.$ 0.002). Post-hoc Duncan's range tests indicated that escape latencies of rats treated with the 5-ng dose of corticosterone were significantly shorter than those treated with vehicle $(P<0.01)$. Lower or higher doses of corticosterone did not significantly alter retention performance.

Figure 3 shows the findings of the second experiment investigating whether immediate post-training infusions of corticosterone into the dorsal striatum enhance memory of spatial training on the water maze. Split-plot ANOVA for escape latencies during training revealed a significant trial effect $\left(F_{(7,301)}=38.76\right.$; $P<0.0001)$, but no group effect $\left(F_{(3,43)}=1.28 ; P=0.29\right)$ or interaction between these two factors $\left(F_{(21,301)}=0.82 ; P=0.70\right)$. Moreover, one-way ANOVA for escape latencies on the 48-h retention test indicated no significant group effect $\left(F_{(3,45)}=0.11\right.$, $P=0.95)$.
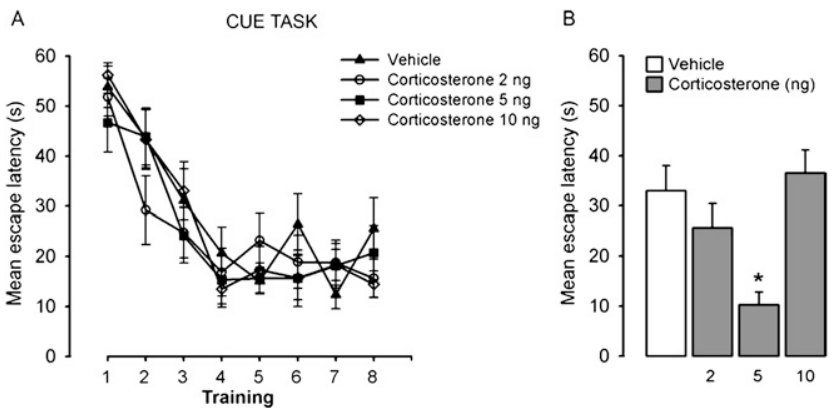

Figure 2. Effect of post-training infusions of corticosterone $(2,5$, or 10 ng) or vehicle into the dorsal striatum on memory consolidation of a cued version of the water maze. $(A)$ Data represent mean escape latencies ( \pm SEM) for each group across trials during the training session. (B) Data represents 48-h testing trial for each group. Vertical lines are standard errors of the means. $\left(^{*}\right)$ Significant difference from vehicle group, $P<0.01$. 

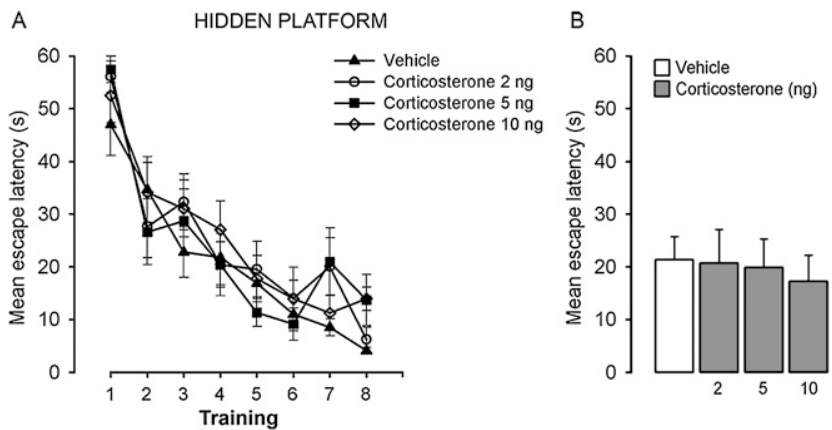

Figure 3. Effect of post-training infusions of corticosterone (2, 5, or 10 ng) or vehicle into the dorsal striatum on memory consolidation of a spatial version of the water maze. $(A)$ Data represent mean escape latencies $( \pm$ SEM) for each group across trials during the training session. (B) Data represents 48-h testing trial for each group. Vertical lines are standard errors of the means.

Thus, these findings indicate that immediate post-training glucocorticoid administration into the dorsal striatum enhanced the retention of procedural/implicit training. The use of posttraining drug administration provides direct support for the view that the corticosterone affected memory consolidation and that the retention performance was thus not confounded by possible effects on attentional, motivational, or sensory-perceptual mechanisms at the time of training (McGaugh 1966). Such a role of the dorsal striatum in regulating glucocorticoid effects on timedependent consolidation processes is consistent with previous evidence that post-training intrastriatal corticosterone infusions enhanced inhibitory avoidance retention when administered either immediately or $30 \mathrm{~min}$, but not $60 \mathrm{~min}$, after training (Medina et al. 2007). In this previous study we found further that infusions of corticosterone given into the neocortex, immediately overlying the dorsal striatum, did not enhance inhibitory avoidance memory (Medina et al. 2007), indicating that the corticosterone effect was mediated by actions in the dorsal striatum, and that the drug did not influence memory consolidation due to spreading along the cannula track. Another interesting finding was that the dose of corticosterone that enhanced memory consolidation of the cued water-maze training experience is the same as that used in the basolateral complex of the amygdala and insular cortex to effectively enhance memory consolidation of conditioned taste aversion learning (Miranda et al. 2008), suggesting that these different forms of memory might be equally sensitive to the memory-modulating effects of glucocorticoids or stressful stimulation.

Our finding that the corticosterone effect on memory consolidation was dose-dependent is in agreement with that of many previous studies (Sandi and Rose 1997; Roozendaal et al. 1999b; Okuda et al. 2004; Medina et al. 2007). Such an inverted $U$-shaped dose-response effect of corticosterone administration on memory consolidation has often been explained by a dose-dependent activation of the high-affinity mineralocorticoid receptor (MR) and the low-affinity glucocorticoid receptor (GR) (Lupien and McEwen 1997). These two receptor types are known to often have opposite effects on neuroplasticity and cellular properties in the hippocampus (Joëls and de Kloet 1994). However, whereas the dorsal striatum expresses a moderate density of GRs (Defiore and Turner 1983; Ahima and Harlan 1990; Ahima et al. 1991; Morimoto et al. 1996), it is virtually devoid of MRs. Moreover, in a previous study we found that the specific GR antagonist RU 38486 administered into the dorsal striatum blocked the enhancing effect of concurrently administered corticosterone on memory consolidation of inhibitory avoidance (Medina et al. 2007). Such findings are consistent with the view that glucocorticoid effects on memory consolidation depend primarily on the GR (Oitzl and de Kloet 1992; Roozendaal and McGaugh 1996; Conrad et al. 1999). Although the mechanism underlying this dose-response effect is unknown, the generality of such a bell-shaped curve across drug systems (e.g., Brioni et al. 1989; Roozendaal et al. 2007) strongly suggests that the ineffectiveness of higher doses in the present study is not caused by any specific characteristics of the corticosterone or its receptor.

The current finding that intrastriatal corticosterone administration enhanced the consolidation of memory of cued, but not spatial training in the water maze is consistent with the evidence that post-training infusions of several other drugs, including amphetamine, into the dorsal striatum selectively enhance memory consolidation of cued water-maze training (Packard et al. 1994, 2001; Packard 2009b). Moreover, post-training drug administration into the dorsal striatum is known to influence the consolidation of memory of the use a procedural, habit-like search strategy on a plus maze (Packard 2009b). In general, these findings are consistent with extensive evidence that the dorsal striatum is involved in the learning and memory of procedural or implicit forms of training. However, recent findings suggest that the dorsal striatum could be subdivided into several functional units that are involved in regulating different aspects of learning and memory: Whereas the dorsolateral division of the dorsal striatum is thought to be particularly involved in mediating procedural/implicit forms of learning and memory (Packard and White 1991; Packard et al. 1994; Packard and Knowlton 2002), the dorsomedial region of the dorsal striatum may support hippocampus-based memories (Devan et al. 1999). Although the infusion volume used in the present study was probably large enough to affect both areas and cannula placement in several rats was within the borders of the dorsomedial region, our finding that corticosterone infused into the dorsal striatum did not enhance memory of water-maze spatial training does not support a role for the dorsal striatum, or for glucocorticoid actions within the dorsal striatum, in hippocampusbased learning and memory.

In summary, the present findings indicate that glucocorticoids act in the dorsal striatum to enhance the consolidation of memory of procedural/implicit forms of learning and add to the view that glucocorticoid hormones have widespread effects throughout the brain to influence memory consolidation in various animal and human memory tasks.

\section{Acknowledgments}

We thank A. Cristina Medina, Angel Méndez, and Martín García for excellent technical assistance. Research was supported by grants UC-MEXUS CN-06-77 (G.L.Q. and B.R.), DGAPA-PAPIITUNAM (IN216708-3), CONACYT 89807 (G.L.Q.), National Science Foundation IOB-0618211 (B.R.), and Graduate Fellowships (I.S.L.) from DGEP-UNAM.

\section{References}

Abercrombie HC, Kalin NH, Thurow ME, Rosenkranz MA, Davidson RJ. 2003. Cortisol variation in humans affects memory for emotionally laden and neutral information. Behav Neurosci 117: 505-516.

Ahima RS, Harlan RE. 1990. Charting of type II glucocorticoid receptor-like immunoreactivity in the rat central nervous system. Neuroscience 39: $579-604$.

Ahima R, Krozowski Z, Harlan R. 1991. Type I corticosteroid receptor-like immunoreactivity in the rat CNS: Distribution and regulation by corticosteroids. J Comp Neurol 313: 522-538.

Andreano JM, Cahill L. 2006. Glucocorticoid release and memory consolidation in men and women. Psychol Sci 17: 466-470.

Brioni JD, Nagahara AH, McGaugh JL. 1989. Involvement of the amygdala GABAergic system in the modulation of memory storage. Brain Res 487: 105-112. 
Buchanan TW, Lovallo WR. 2001. Enhanced memory for emotional material following stress-level cortisol treatment in humans. Psychoneuroendocrinology 26: 307-317.

Conrad CD, Lupien SJ, McEwen BS. 1999. Support for a bimodal role for type II adrenal steroid receptors in spatial memory. Neurobiol Learn Mem 72: $39-46$.

de Kloet ER, Oitzl MS, Joëls M. 1999. Stress and cognition: Are corticosteroids good or bad guys? Trends Neurosci 22: 422-426.

Defiore CH, Turner BB. 1983. [ $\left.{ }^{3} \mathrm{H}\right]$ corticosterone binding in the caudateputamen. Brain Res 278: 93-101.

Devan BD, McDonald RJ, White NM. 1999. Effects of medial and lateral caudate-putamen lesions on place- and cue-guided behaviors in the water maze: Relation to thigmotaxis. Behav Brain Res 100: 5-14.

Hui GK, Figueroa IR, Poytress BS, Roozendaal B, McGaugh JL, Weinberger NM. 2004. Memory enhancement of classical fear conditioning by posttraining injections of corticosterone in rats. Neurobiol Learn Mem 81: 67-74.

Joëls M, de Kloet ER. 1994. Mineralocorticoid and glucocorticoid receptors in the brain: Implications for ion permeability and transmitter systems. Prog Neurobiol 43: 1-36.

Joëls M, Pu ZW, Wiegert O, Oitzl MS, Krugers HJ. 2006. Learning under stress: How does it work? Trends Cogn Sci 10: 152-158.

Kim JJ, Lee HJJ, Han JS, Packard MG. 2001. Amygdala is critical for stressinduced modulation of hippocampal long-term potentiation and learning. J Neurosci 21: 5222-5228.

Kuhlmann S, Wolf OT. 2006. Arousal and cortisol interact in modulating memory consolidation in healthy young men. Behav Neurosci 120: $217-223$.

Lupien SJ, McEwen BS. 1997. The acute effects of corticosteroids on cognition: Integration of animal and human model studies. Brain Res Brain Res Rev 24: 1-27.

McGaugh JL. 1966. Time-dependent processes in memory storage. Science 153: $1351-1358$

Medina AC, Charles JR, Espinoza-Gonzalez V, Sanchez-Resendis O, Prado-Alcalá RA, Roozendaal B, Quirarte GL. 2007. Glucocorticoid administration into the dorsal striatum facilitates memory consolidation of inhibitory avoidance training but not of the context or footshock components. Learn Mem 14: 673-677.

Miranda MI, Quirarte GL, Rodriguez-Garcia G, McGaugh JL, Roozendaal B. 2008. Glucocorticoids enhance taste aversion memory via actions in the insular cortex and basolateral amygdala. Learn Mem 15: 468-476.

Morimoto M, Morita N, Ozawa H, Yokoyama K, Kawata M. 1996. Distribution of glucocorticoid receptor immunoreactivity and mRNA in the rat brain: An immunohistochemical and in situ hybridization study. Neurosci Res 26: 235-269.

Oitzl MS, de Kloet ER. 1992. Selective corticosteroid antagonists modulate specific aspects of spatial orientation learning. Behav Neurosci 106: 62-71.

Okuda S, Roozendaal B, McGaugh JL. 2004. Glucocorticoid effects on object recognition memory require training-associated emotional arousal. Proc Natl Acad Sci 101: 853-858.

Packard MG. 2009a. Anxiety, cognition, and habit: A multiple memory systems perspective. Brain Res. doi: 1016/j.brainres.2009.03.029.

Packard MG. 2009b. Exhumed from thought: Basal ganglia and response learning in the plus-maze. Behav Brain Res 199: 24-31.

Packard MG, Knowlton BJ. 2002. Learning and memory functions of the basal ganglia. Annu Rev Neurosci 25: 563-593.

Packard MG, White NM. 1991. Dissociation of hippocampus and caudate nucleus memory systems by posttraining intracerebral injection of dopamine agonists. Behav Neurosci 105: 295-306.

Packard MG, Cahill L, McGaugh JL. 1994. Amygdala modulation of hippocampal-dependent and caudate nucleus-dependent memory processes. Proc Natl Acad Sci 91: 8477-8481.
Packard MG, Vecchioli SF, Schroeder JP, Gasbarri A. 2001. Task-dependent role for dorsal striatum metabotropic glutamate receptors in memory. Learn Mem 8: 96-103.

Paxinos G, Watson C. 1998. The rat brain in stereotaxic coordinates. Academic Press, New York.

Plihal W, Born J. 1999. Memory consolidation in human sleep depends on inhibition of glucocorticoid release. Neuroreport 10: 2741-2747.

Prado-Alcalá RA, Ruiloba MI, Rubio L, Solana-Figueroa R, Medina C, SaladoCastillo R, Quirarte GL. 2003. Regional infusions of serotonin into the striatum and memory consolidation. Synapse 47: 169-175.

Pugh CR, Tremblay D, Fleshner M, Rudy JW. 1997. A selective role for corticosterone in contextual-fear conditioning. Behav Neurosci 111: 503-511.

Roozendaal B. 2000. Glucocorticoids and the regulation of memory consolidation. Psychoneuroendocrinology 25: 213-238.

Roozendaal B, McGaugh JL. 1996. Amygdaloid nuclei lesions differentially affect glucocorticoid-induced memory enhancement in an inhibitory avoidance task. Neurobiol Learn Mem 65: 1-8.

Roozendaal B, Nguyen BT, Power AE, McGaugh JL. 1999a. Basolateral amygdala noradrenergic influence enables enhancement of memory consolidation induced by hippocampal glucocorticoid receptor activation. Proc Natl Acad Sci 96: 11642-11647.

Roozendaal B, Williams CL, McGaugh JL. 1999b. Glucocorticoid receptor activation in the rat nucleus of the solitary tract facilitates memory consolidation: Involvement of the basolateral amygdala. Eur J Neurosci 11: $1317-1323$.

Roozendaal B, Okuda S, Van der Zee EA, McGaugh JL. 2006. Glucocorticoid enhancement of memory requires arousal-induced noradrenergic activation in the basolateral amygdala. Proc Natl Acad Sci 103: 6741-6746.

Roozendaal B, Lengvilas R, McGaugh JL, Civelli O, Reinscheid RK. 2007. Orphanin $\mathrm{FQ} /$ nociceptin interacts with the basolateral amygdala noradrenergic system in memory consolidation. Learn Mem 14: $29-35$.

Roozendaal B, Barsegyan A, Lee S. 2008. Adrenal stress hormones, amygdala activation, and memory for emotionally arousing experiences. In Stress hormones and post-traumatic stress disorder: Basic studies and clinical perspectives (eds. ER DeKloet et al.), pp. 79-96. Elsevier Science, The Netherlands.

Sandi C, Rose SP. 1997. Training-dependent biphasic effects of corticosterone in memory formation for a passive avoidance task in chicks. Psychopharmacology 133: 152-160.

Sandi C, Pinelo-Nava MT. 2007. Stress and memory: Behavioral effects and neurobiological mechanisms. Neural Plast 2007: 78970. doi: 10.1155/ $2007 / 78970$

Sandi C, Loscertales M, Guaza C. 1997. Experience-dependent facilitating effect of corticosterone on spatial memory formation in the water maze. Eur J Neurosci 9: 637-642.

Schwabe L, Dalm S, Schächinger H, Oitzl MS. 2008. Chronic stress modulates the use of spatial and stimulus-response learning strategies in mice and man. Neurobiol Learn Mem 90: 495-503.

Schwabe L, Oitzl MS, Richter S, Schachinger H. 2009. Modulation of spatial and stimulus-response learning strategies by exogenous cortisol in healthy young women. Psychoneuroendocrinology 34: 358-366.

Wachter T, Lungu OV, Liu T, Willingham DT, Ashe J. 2009. Differential effect of reward and punishment on procedural learning. J Neurosci 29: 436-443.

Zorawski M, Killcross S. 2002. Posttraining glucocorticoid receptor agonist enhances memory in appetitive and aversive Pavlovian discrete-cue conditioning paradigms. Neurobiol Learn Mem 78: 458-464.

Received June 3, 2009; accepted in revised form July 31, 2009. 


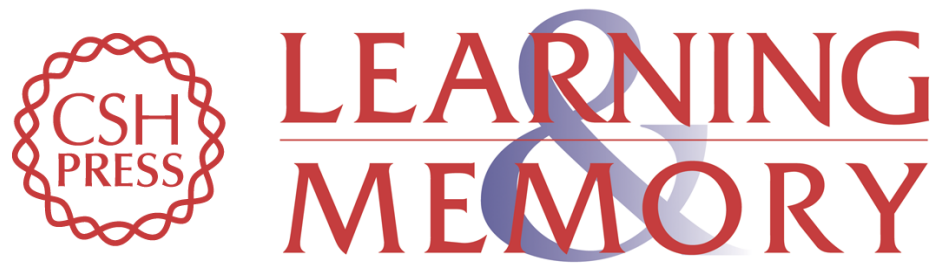

\section{Corticosterone infused into the dorsal striatum selectively enhances memory consolidation of cued water-maze training}

Gina L. Quirarte, I. Sofía Ledesma de la Teja, Miriam Casillas, et al.

Learn. Mem. 2009, 16:

Access the most recent version at doi:10.1101//m.1493609

References This article cites 44 articles, 11 of which can be accessed free at:

http://learnmem.cshlp.org/content/16/10/586.full.html\#ref-list-1

License

Email Alerting Receive free email alerts when new articles cite this article - sign up in the box at the Service top right corner of the article or click here. 